\title{
ANIMAL WELL-BEING BIOLOGICAL HAZARD ASSESSMENT FOR TRANSPORT LOGISTICS IN SUSTAINABLE AGRICULTURE IN THE REPUBLIC OF POLAND
}

\author{
Jacek WASILEWSKI, Małgorzata SZCZEPANIK, Zbigniew BURSKI \\ University of Life Sciences in Lublin, POLAND \\ E-mail of corresponding author: malgorzata.szczepanik@up.lublin.pl
}

Keywords: sustainable agriculture, animal well-being, transport logistics, biological hazard, correlation analysis

\begin{abstract}
This paper presents the findings of the cattle well-being in transport audit conducted in the period from 2007 till 2012. Respective veterinary check-ups were audited: upon dispatch, upon arrival, at rest, sale (at markets or cattle collection points), and in-transport checks. The number of cattle heads subject to the audit, the number of cattle heads that proved irregularities and correlations between those numbers in the previous years were analysed. Moreover, the audit of the percentage share of the animals that had proven irregularities has allowed for accurate assessment of irregularities occurrence rate. Positive correlation between the percentage share of the cattle heads that proved irregularities and the audit years has been found.
\end{abstract}

\section{INTRODUCTION}

Animal well-being assurance is one of the most significant issues for the sustainable agriculture. The well-being must be understood as animals' condition of physical and mental health achieved in harmony with natural environment (Kołacz 2005).

Animal and food products transport development is strictly connected with the natural environment protection and security (Bauer et al. 2010, García-Álvarez et al. 2013, Krautzberger and Wetzel 2012). Other transport issues are additionally subject to the law and legal regulations in force in the European Union. This is the case with the competition among carriers, employment conditions, vehicle technical standards and related energy consumption rates as well as terrorism threat anticipation and possible loss cuts (Black 2002, Burski et al. 2016, Drewes et al. 2003, Stead 2001).

Animal and food products transport is a specific kind of transport that has required diligence and technical and sanitary standards compliance (Raiten and Aimone 2017, Barlow et al. 2015). Therefore, there is the need for defining current hazards in transport of this kind in respective Member States in the European Union, alongside the veterinary standards compliance. This is the aim of this publication in which wheeled means of animal (cattle) transport have been scrutinised in the context of completed audits and related irregularities that have been found in the recent years in Poland and the correlation analysis that has been carried out.

\section{FINDINGS OF CATTLE WELL-BEING IN-TRANSPORT AUDIT}

The findings of the number of the cattle heads audited in terms of animal well-being in the period from 2007 until 2012 at respective transport stages have been displayed in the Figure 1. 


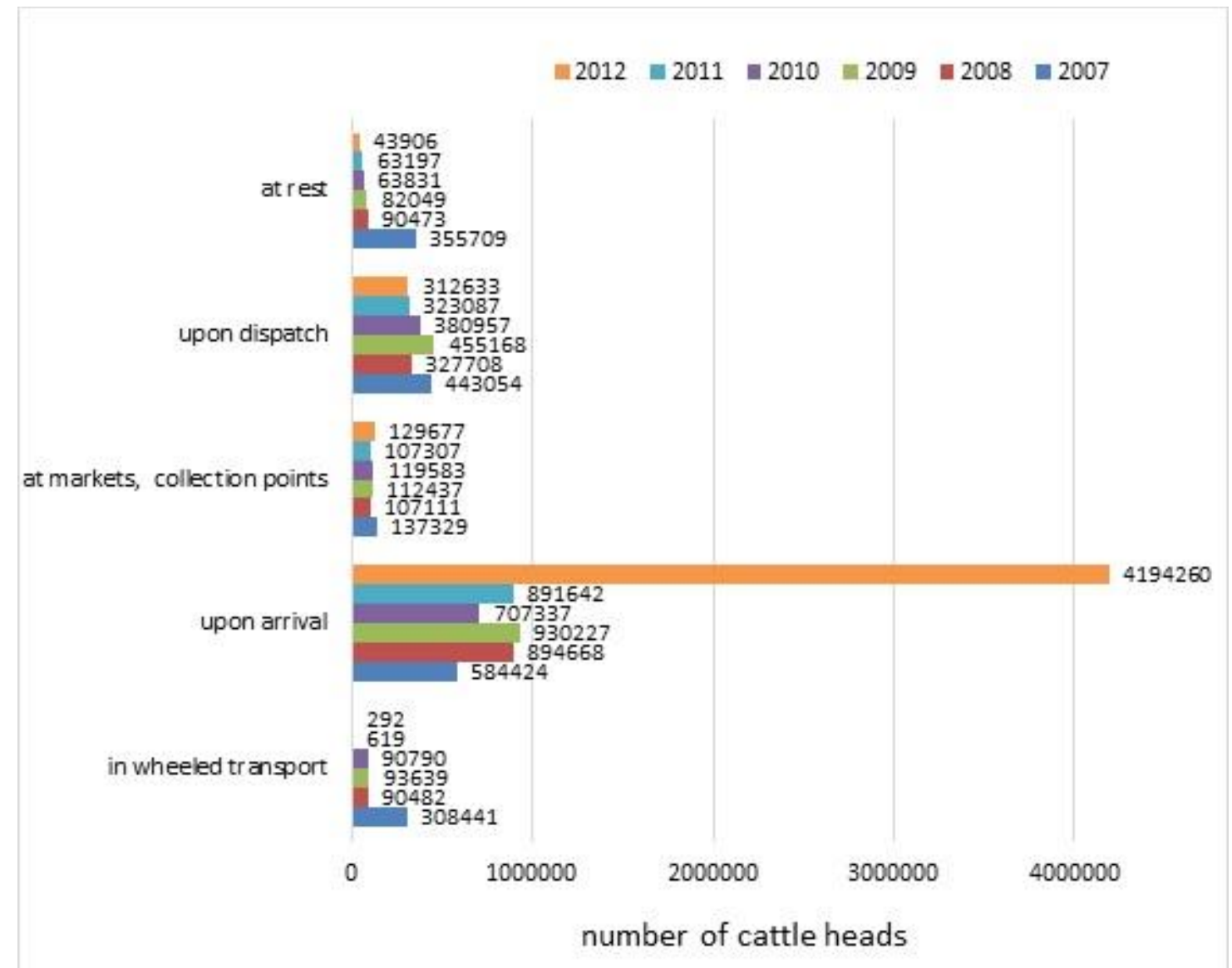

Figure 1. Number of cattle heads that was subject to means of transport audit in the period from 2007 till 2012 (own study based on Integrated Multiannual..., 2007-2012)

The number of cattle that was subject to the wheeled transport audit fell in the majority of cases in consecutive years (except for the year 2009): from 308441 in 2007 down to 292 in 2012 (Figure 1). The largest number of cattle heads i.e., 4194260 were audited upon arrival in 2012. The number of animals audited at markets or cattle collection points was more or less steady in the audited period and amounted to 107111 pieces in 2008 up to 137329 in 2007 . The number of cattle heads that were subject to check-ups during rest fell in consecutive years and in the case of audit upon dispatch - beginning with 2009.

The number of cattle heads that proved irregularities found in the means of transport audit has been presented in the Figure 2 . 


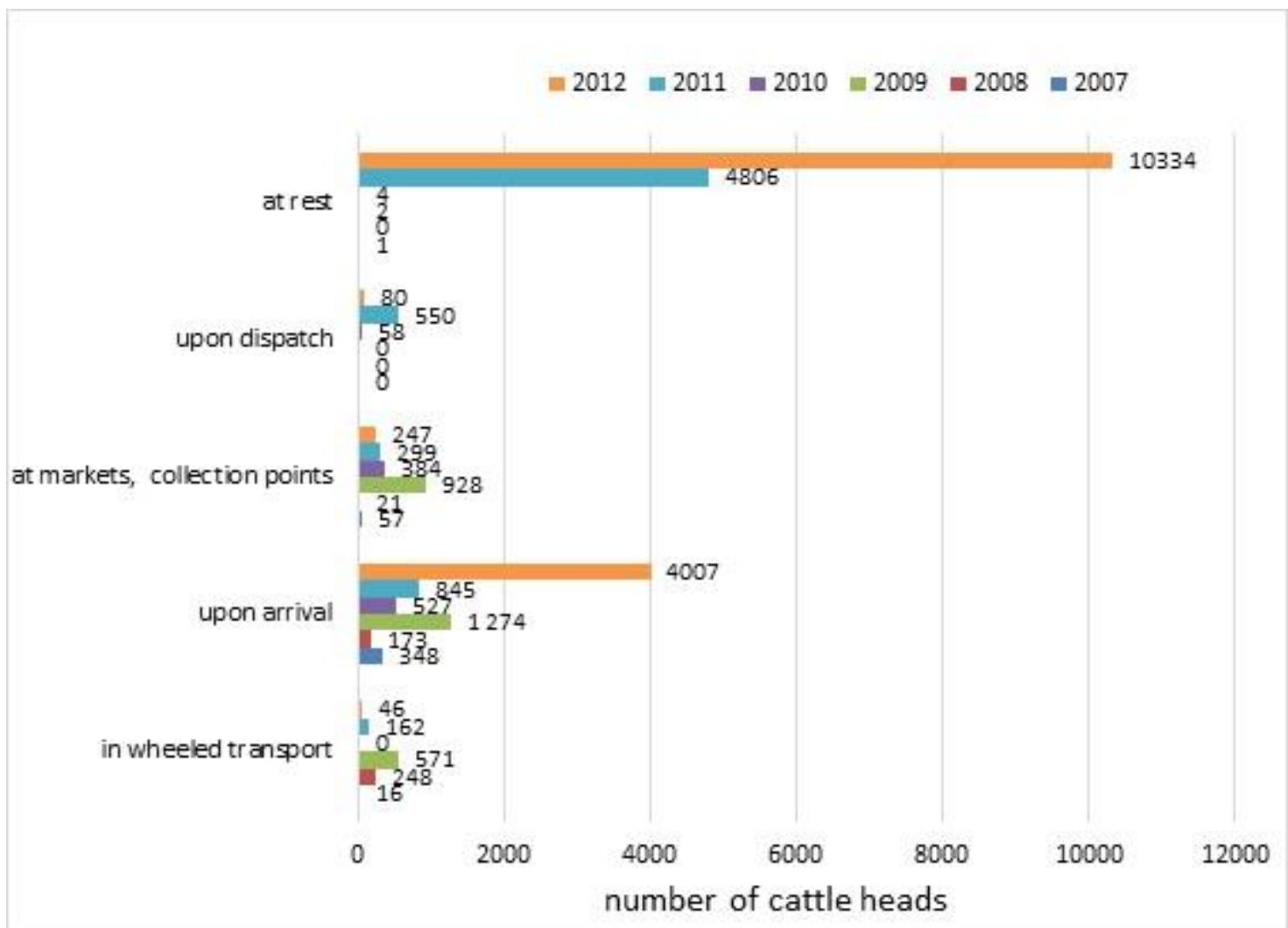

Figure 2. Number of cattle heads that proved irregularities found in means of transport audit in the period from 2007 until 2012 (own study based on Integrated Multiannual..., 2007-2012)

The change in the number of cattle heads that proved irregularities did not indicate a clear tendency (Figure 2). Upon arrival in 2012 irregularities were found for the largest number i.e., 4007 of cattle heads. In the case of audits carried out at markets and animal collection points, the number of animals that proved irregularities fell beginning with 2010. It bears noting that in the period from 2007 until 2009 no irregularities were found among the audited cattle upon dispatch. During the remaining period, the largest number of irregularities were found in the years 2011 and 2012 (4806 and 10334 cattle heads, respectively) whereas in the remaining years irregularities were found for just few cattle heads or were not found at all (in 2008).

\section{CATTLE AUDIT FINDINGS CORRELATION ANALYSIS}

Interdependences between the number of cattle heads subject to the audit, the number of cattle heads that proved irregularities and the years of audit have been presented by means of the correlation coefficients (Table 1) alongside the audit venues.

The strong negative correlation between consecutive years and the number of cattle heads subject to the audit in transport has been found (Table $1, r=-0.86$ ). No significant correlation between the number of audited cattle heads and the number of cattle heads that proved irregularities has been found $(r=-0.17)$.

The analysis of the audit upon arrival has indicated the moderate positive correlation between consecutive years and the number of cattle heads subject to the audit $(r=0.68)$ as well as consecutive years and the number of cattle heads that proved irregularities $(r$ $=0.73$ ). The correlation between the number of cattle heads subject to the audit and the 
number of cattle heads that proved irregularities has been found positive and extremely strong $(r=0.97)$.

Table 1. Correlation coefficients (r)

\begin{tabular}{|c|c|c|c|}
\hline audit & examined feature & years & $\begin{array}{l}\text { number of cattle heads } \\
\text { that proved irregularities }\end{array}$ \\
\hline \multirow[b]{2}{*}{ in wheeled transport } & number of cattle heads & -0.86 & -0.17 \\
\hline & $\begin{array}{l}\text { number of cattle heads that proved } \\
\text { irregularities }\end{array}$ & -0.17 & \\
\hline \multirow{2}{*}{ upon arrival } & number of cattle heads & 0.68 & 0.97 \\
\hline & $\begin{array}{l}\text { number of cattle heads that proved } \\
\text { irregularities }\end{array}$ & 0.73 & \\
\hline \multirow{2}{*}{$\begin{array}{l}\text { at markets, collection } \\
\text { points }\end{array}$} & number of cattle heads & -0.13 & -0.28 \\
\hline & $\begin{array}{l}\text { number of cattle heads that proved } \\
\text { irregularities }\end{array}$ & 0.20 & \\
\hline \multirow[b]{2}{*}{ upon dispatch } & number of cattle heads & -0.63 & -0.47 \\
\hline & $\begin{array}{l}\text { number of cattle heads that proved } \\
\text { irregularities }\end{array}$ & 0.52 & \\
\hline \multirow[b]{2}{*}{ at rest } & number of cattle heads & -0.75 & -0.40 \\
\hline & $\begin{array}{l}\text { number of cattle heads that proved } \\
\text { irregularities }\end{array}$ & 0.83 & \\
\hline \multirow[b]{2}{*}{ total } & number of cattle heads & 0.56 & 0.87 \\
\hline & $\begin{array}{l}\text { number of cattle heads that proved } \\
\text { irregularities }\end{array}$ & 0.84 & \\
\hline
\end{tabular}

The number of audited cattle head upon dispatch fell, which corresponds to the negative and moderate correlation between consecutive years and the number of audited cattle heads $(r=-0.63)$.

The analysis of the audit at rest has indicated the strong and negative correlation between the number of cattle heads and consecutive years $(r=-0.75)$ as well as the strong and positive correlation between the years and the number of cattle heads that proved irregularities $(\mathrm{r}=0.83)$.

After having summed up the number of audited cattle heads in consecutive years, the positive and moderate $(\mathrm{r}=0.56)$ correlation between the number of audited cattle heads and consecutive years as well as the strong positive correlation between the number of cattle heads that proved irregularities and consecutive years $(r=0.84)$ have been found. The correlation between the number of audited cattle heads and the number of cattle heads that proved irregularities has been positive and strong $(r=0.87)$.

The percentage share of the cattle heads that proved irregularities, namely the quotient of the number of cattle heads that proved irregularities and the number of cattle heads subject to the audit has been additionally analysed. The correlation coefficients between consecutive years and the percentage share of irregularities have been computed. The results have been presented in the Table 2 . 
Table 2. The percentage share of cattle that proved irregularities and correlation coefficients (r) for the percentage share and consecutive years

\begin{tabular}{|l|c|c|c|c|c|c|c|}
\hline \multicolumn{1}{|c|}{ audit } & 2007 & 2008 & 2009 & 2010 & 2011 & 2012 & $\mathrm{r}$ \\
\hline in wheeled transport & $0.01 \%$ & $0.27 \%$ & $0.61 \%$ & $0.00 \%$ & $26.17 \%$ & $15.75 \%$ & 0.74 \\
\hline upon arrival & $0.06 \%$ & $0.02 \%$ & $0.14 \%$ & $0.07 \%$ & $0.09 \%$ & $0.10 \%$ & 0.46 \\
\hline $\begin{array}{l}\text { at markets, collection } \\
\text { points }\end{array}$ & $0.04 \%$ & $0.02 \%$ & $0.83 \%$ & $0.32 \%$ & $0.28 \%$ & $0.19 \%$ & 0.19 \\
\hline upon dispatch & $0.00 \%$ & $0.00 \%$ & $0.00 \%$ & $0.02 \%$ & $0.17 \%$ & $0.03 \%$ & 0.52 \\
\hline at rest & $0.00 \%$ & $0.00 \%$ & $0.00 \%$ & $0.01 \%$ & $7.60 \%$ & $23.54 \%$ & 0.79 \\
\hline total & $0.02 \%$ & $0.03 \%$ & $0.14 \%$ & $0.07 \%$ & $0.48 \%$ & $0.31 \%$ & 0.80 \\
\hline
\end{tabular}

The highest percentage share of irregularities amongst the cattle (Table 2) has been found in the case of the audit in wheeled transport in $2011(26.17 \%)$ and in 2012 $(15.75 \%)$ as well as in the years 2012 and 2011 for the audit at rest $(23.54 \%$ and $7.60 \%$, respectively). The correlations between the percentage share of irregularities and consecutive years have been found positive. The strong correlation has been found between the consecutive years and the percentage share of irregularities in the case of the audit in wheeled transport $(\mathrm{r}=0.74)$ and at rest $(\mathrm{r}=0.79)$. The correlation between the percentage share of irregularities and total consecutive years for the total number of audited cattle heads has been found very strong $(r=0.80)$.

\section{CONCLUSIONS}

The study that has been conducted indicates that the number of cattle heads that were audited fell in the consecutive years. The audits upon arrival (slaughter-houses, abattoirs) were the exceptions to have posted the rising number of audited cattle heads in the period from 2007 until 2009 and 2010 till 2012. The largest number of audited cattle heads was reported for the audit upon arrival.

No uniform tendencies have been spotted in the case of irregularities referring to animal well-being. The largest volume of irregularities was found at the place of rest in 2012.

The analysis of the correlations between the number of audited cattle heads and the number of cattle heads that proved irregularities and the consecutive years of the study has provided for an interesting outcome. There is a very strong negative correlation between the consecutive years and the number of audited cattle heads $(r=-0.86)$ in transport as well as at rest $(r=-0.75)$. Furthermore, most often positive (except for the audit in wheeled transport) correlations between the number of cattle heads that proved irregularities and the consecutive years have been found. The strongest correlations have been found for the audit at rest and upon arrival.

The analysis of the percentage share of cattle heads that proved irregularities has provided for unambiguous assessment of the irregularity occurrence rate. The highest percentage share of irregularities has been found for the audit conducted in 2011 and 2012 in wheeled transport and at rest.

The resulting figures of the correlation analysis conducted to the extent of the cattle well-being are very much interesting and should serve the basis for assessment of the 
outstanding issue under consideration since there are significant differences in the assessment of well-being among the audit upon dispatch, upon arrival, and in transport. Explanation of this phenomenon should be the subject matter of the audit of veterinary authorities since it has an impact upon animal quality features that are so essential in terms of assessment, consumption merits, and animals themselves. A similar analysis should be conducted for other animals - maybe transported in smaller numbers - sheep, chicken, geese, etc.

Familiarity with the factors that have the impact upon animals' well-being may not only be the faults occurring within the framework of domestic transport but may also be the target of the impact of terrorism threats in international terms - biological, chemical, radiological hazards. It is currently one of the most important issues in terms of global threat for vehicle inspection authorities, the police, veterinary authorities.

\section{REFERENCES}

Barlow, S. M., Boobis, A. R., Bridges, J., Cockburn, A., Dekant, W., Hepburn, P., Houben, G. F., König, J., Nauta, M. J., Schuermans, J., Bánáti, D. (2015). The role of hazard- and risk-based approaches in ensuringfood safety. Trends in Food Science \& Technology, 46 (2), Part A, 176-188.

Bauer, J., Bektas, T., Crainic, T.G. (2010). Minimizing greenhouse gas emissions in intermodal freight transport: an application to rail service design. J. Oper. Res. Soc. 61, 530-542.

Black, W. R. (2002). Sustainable transport and potential mobility. Eur. J. Trans. Infrastruct. Res., 2 (34), 179-196.

Burski, Z., Mijalska-Szewczak, I., Wasilewski, J., Szczepanik, M. (2016). Evaluation of energy consumption of vehicles in EU Trans-European Transport Network. Transportation Research Part A 92, 120-130.

Drewes, N., Jaspersen, H., Petersen, T. (2003). Freight transport growth - a theoretical and methodological framework. Eur. J. Oper. Res. 144, 295-305.

García-Álvarez, A., Pérez-Martínez, P. J., González-Franco, I. (2013). Energy consumption and carbon dioxide emissions in rail and road freight transport in Spain: a case study of car carriers and bulk petrochemicals. J. Intell. Transport. Syst., Technol., Plan., Oper. 17 (3), 233-244.

Kołacz, R. (2005). Etyczne i prawne aspekty dobrostanu zwierząt. Interservice. Conf. VetMedica, Łódź, Poland, 20-21 maja, 11-15.

Krautzberger, L., Wetzel, H. (2012). Transport and $\mathrm{CO}_{2}$ : productivity growth and carbon dioxide emissions in the European commercial transport industry. Environ. Resource Econ. 53 (3), 435-454.

Raiten, D. J., Aimone, A. M. (2017). The intersection of climate/environment, food, nutrition and health: crisis and opportunity. Current Opinion in Biotechnology, 44, 52-62.

Stead, D. (2001). Transport intensity in Europe - indicators and trends. Transport Policy, 8(1), 29-46.

Integrated MultiAnnual National Control Plan for Poland: 2007-2012. Annual reports 2008-2013. Warsaw. 